\title{
O JAZZ e 0 NEOPLASTICISMO
}

\author{
PIET MONDRIAN
}

\section{RESUMO}

O jazz e o neoplasticismo surgem como expressões de uma nova vida. Exprimem ao mesmo tempo a alegria e a seriedade que estão ausentes em nossas formas culturais exauridas. Surgem com movimentos simultâneos em várias esferas da realidade que tentam se opor à forma individual e à emoção subjetiva: não aparecem mais como expressões do "belo", mas como "vida" que se manifesta através do puro ritmo.

PALAVRAS-CHAVE: jazz; neoplasticismo; Mondrian; artes plásticas.

\section{SUMMARY}

Jazz and neoplasticism are expressions of a new life. They express at once the joy and seriousness that are missing in our exhausted cultural forms. They appear as simultaneous movements in many spheres of reality that try to resist to individual form and subjective emotion: they don't appear as expressions of "beauty", but as "life" that manifests itself through pure rhythm.

KEYWORDS: jazz; neoplasticism; Mondrian; fine arts.

[1] "Jazz and Neo-Plastic". Mondrian, Piet. "De Jazz en de NeoPlastiek", i 10 1, n 12, dez. 1927). In: Holtzman, H. e Martin, S. J. (orgs.), The new art - The new life. The collected writings of Piet Mondrian. Londres: Thames \& Hudson, 1987, pp. 217-22, trad. de Vera Pereira. [O comentário introdutório é da edição em inglês.] Este texto foi gentilmente cedido pela CosacNaify. Para um conjunto de ensaios de teor semelhante, ver Mondrian, Piet. Neoplasticismo na pintura e na arquitetura. São Paulo: CosacNaify, 2008.

[2] Félix Del Marle, pintor francês (1889-1952), inicialmente futurista e depois adepto do neoplasticismo. [N.T.]

[3] Bois, "Mondrian en France", document 17,294.

[4] J. J. P. Oud, arquiteto, amigo de Mondrian, também fazia parte do grupo De Stijl. [N.T.]
O artigo "De jazz en de Neo-Plastiek" foi publicado originalmente em holandês no número de dezembro de 1927 da revistailo.

Nesse texto, as preocupações musicais, pictóricas, filosóficas e sociais de Mondrian se concentram no ambiente coletivo do "bar", ou clube noturno. A preocupação com o entorno foi um estímulo importante para a elaboração do artigo, conforme demonstram duas cartas do artista escritas durante o verão de 1927. No dia 25 de agosto, Mondrian escreveu a Del Marle², dizendo que passara mais de dois meses trabalhando na decoração do seu ateliê: "Aprendi muito, ou melhor, tantas coisas ficaram tão evidentes para mim que fui tomado pelo impulso de escrever um artigo"3. E dois dias depois, isto é, em 27 de agosto, ele declarou em outra carta, desta vez dirigida a Oud4: "Estou ocupado em escrever um artigo sobre o neoplasticismo cromoplástico em arquitetura. [...] O jazz nada mais é que um ponto de partida; o texto não trata de música". 
"Leste meu artigo na revista i 10 ?", Mondrian pergunta mais tarde (em 4 de dezembro) ao mesmo Oud. "Parece ter relevância cultural, como você disse certa vez numa palestra sobre o meu trabalho. [...] Eu gostaria de fazer uma série de artigos: uma espécie de reflexão artístico-filosófica sobre o neoplasticismo."

No ano anterior, ao tomar conhecimento de que o charleston poderia ser proibido na Holanda por causa de sua "sensualidade", Mondrian declarou, indignado, durante uma entrevista:

Sim, dançado da maneira nervosa e excitada dos europeus, [o charleston] muitas vezes dá a impressão de histérico. Mas no caso dos negros, de uma Josephine Baker, por exemplo, é um estilo natural e maravilhosamente controlado. Todas as danças modernas parecem capengas se comparadas àquela contínua e vigorosa concentração de velocidade. Como se pode pensar em proibir na Holanda essa dança tão cheia de vitalidade? Os dançarinos se mantêm sempre tão afastados entre si e têm de movimentarse de maneira tão árdua que não sobra tempo para idéias amorosas. Se proibirem o charleston, este será um motivo para que eu jamais volte a pôr os pés neste país 5 .

[5] De Telegraaf, 12 set. 1926.

A lheios à melodia eà forma que nos cercam, o jazz e o neoplasticismo surgem como expressões deuma novavida.Exprimem ao mesmo tempo a alegria e a seriedade que estão ausentes em nossas formas culturais exauridas. Surgem com movimentos simultâneos em várias esferas da realidade que tentam se opor à forma individual e à emoção subjetiva: não aparecem mais como expressões do "belo", mas como "vida" que se manifesta através do puro ritmo, o qual expressa unidade por não ser fechado. Muitos movimentos pretendem abolir a forma e criar um ritmo mais livre. $\mathrm{Na}$ arte, o futurismo deu o impulso importante nessa direção. O cubismo levou a pintura a quebrar a forma e a organizá-la de outra maneira. Menos condicionada pela forma que as outras artes, a pintura conseguiu levar adiante esse projeto de modo coerente no neoplasticismo: uma nova organização realizada por novos meios plásticos. A literatura, por outro lado, era limitada pelas palavras e frases; mas, como arte, também podia se tornar, em certa medida, uma expressão plástica de puro ritmo. Ao excluir-se a lógica (que faz a literatura racional parecer sem sentido, mas queé, no entanto, bastante factível na arte), a forma foi rompida, aniquilada, e o ritmo se libertou.

Entretanto, as palavras ou frases conservaram seus significados individuais, tal como se deu com a forma no cubismo. Quando esses significados são abolidos pela redução das palavras a puros sons, a literatura perde seu significado como tal e se aproxima da música. Desse modo, suas potencialidades são restringidas. A músi- 
ca também sofreu influência do espírito da época e foi igualmente reformada. Contudo, ela não obteve resultados comparáveis aos da pintura, pois se manteve presa a princípios convencionais e aos instrumentos existentes. Com novos conceitos e técnicas, a música também poderia expressar-se como pura plástica (veja-se o livro $\mathrm{n}^{\mathrm{O}} 5$ da Bauhaus, Die Neue Gestaltung [A nova forma]). "Quanto mais uma forma de arte é limitada pela forma, mais difícil será para ela alcançar uma expressão plástica universal, uma nova ordem." É óbvio, então, que a própria vida tem enorme dificuldade para lidar com a pureza e a ordem universal. Cada vez mais, ela tende a servista como diferente da matéria e vivida de maneira mais abstrata. O que pode ser realizado na arte tem se tornado cada vez mais possível na vida. $A$ cultura aos poucos libertará a vida da opressão da matéria, até amadurecer e tornar-se uma nova cultura.

Livre de convenções musicais, o jazz cria quase que um ritmo puro, graças à intensidade de seus efeitos e contrastes sonoros. $O$ ritmo do jazz já lhe proporciona uma ilusão de "abertura", de liberdade. $O$ neoplasticismo, por outro lado, exibe um ritmo efetivamente livre da forma, um ritmo universal. Isso porque o neoplasticismo concretiza os fundamentos da pintura neoplástica na totalidade de nosso ambiente construído, pois é o princípio da concretização na vida de uma nova ordem mais universal.

Daí decorre a importância do neoplasticismo para a cultura: sua realização material é convincente. A idéia de ordem universal foi "formulada" há tempos pela filosofia tanto de modo intuitivo quanto racional, mas somente em nossa época a idéia se tornou consciente e repercutiu na sociedade. Somente agora sua materialização se torna visível. Noções de pureza e ordem vêm aparecendo em muitas áreas. Muitos obstáculos refletem a carência de profundidade necessária à instauração da nova ordem na vida, profundidade que é desigual entre indivíduos desiguais. Durante algum tempo, a nova cultura será a expressão de um pequeno grupo. As massas ficarão para trás, pois estão em um processo de adquirir instrução, e é lógico que se apeguem à velha cultura e se oponham ao novo.

O ritmo universal na nova cultura expressa integralmente a vida humana. Entretanto, em um sentido mais profundo, o ritmo universal não se pode concretizar em nosso mundo. Avelha cultura tentou fazêlo, separando a natureza do espírito; dividiu assim a vida nos planos material e espiritual. Compreendendo que era impossível concretizar essa universalidade mais profunda, ela se concentrou exclusivamente na vida material. A velha cultura ainda não estava madura o bastante para resolver essa dualidade.

$\mathrm{Na}$ vida real, os sinais que indicam o amadurecimento cultural ainda são poucos e incertos, eé difícil medir o grau de consciência. Mas 
os fenômenos observáveis pela primeira vez no conjunto da cultura são indubitáveis. O fato de que, tendo rompido com a forma, a arte está próxima de seu fim e preparada para diluir-se na própria vida é um dos sinais inegáveis de uma cultura da forma em maturação.

Tudo leva a crer, portanto, que chegamos a um ponto de inflexão na cultura humana. Nossa mentalidade demonstra claramente que, para essa cultura, a "forma" atingiu um ponto final. Isso quer dizer que não desejamos mais as limitações da forma, embora continuemos a aperfeiçoar a forma das coisas materiais quando necessário. Do ponto de vista moral, estamos, portanto, no fim da cultura da forma e no começo de uma nova cultura que começa a se expressar inconscientemente por meio da forma - ou seja, por meio das relações. A cultura das relações levará a uma relação universal, que por si só conseguirá abolir completamente todas as formas.

Tal passagem da arte para a vida se mostra mais claramente no jazz e no neoplasticismo. É verdade que ambos se restringem à esfera auditiva e visual, mas essa esfera está agora tão estreitamente associada à vida que já nos parece concreta.

O jazz e o neoplasticismo são fenômenos revolucionários ao extremo: simultaneamente destrutivos e construtivos. Eles não eliminamo conteúdo literal da forma, apenas a aprofundam e destroem em benefício de uma nova ordem. Ao romper os limites da "forma como particularidade", tornam possível a unidade universal.

O jazz sincopado americano, ou melhor, o jazz negro, é bem conhecido, embora difícil de encontrar. É possível ouvi-lo em gravações das maiores bandas de jazz americanas e européias, e também no "bar" [clube noturno]. O neoplasticismo puro, ao contrário, só é encontrável de maneira aproximada, aqui e ali. Seu conteúdo, porém, pode ser percebido de imediato na pintura neoplástica, que é bastante conhecida. A natureza e o grau de sua concretização têm pouca importância. $O$ fato essencial é ter se concretizado como expressão de um grupo que o aceita ou o cria conscientemente, conforme permitam as circunstâncias.

Assim como a cultura da forma, a psicologia da forma está chegando ao fim. Uma vez abolida a forma, todas as coisas se unificam. O homem então já não vive mais em um mundo privado e isolado, mas dentro do mundo: passa a ser verdadeiramente uma parte dele - separada, mas atuante. Já não é uma máquina, mas um ser consciente e integralmente "humano". Ele usa a máquina, em vez de ser incorretamente usado [ou maltratado] por ela, como acontece hoje. A máquina não éa nova cultura; é um dos meios pelos quais opera a velha cultura da forma (para o bem ou para o mal, nos dias de hoje, mas na linha geral da cultura, conjuntamente para o bem). A máquina nivela tudo, tal como o militarismo. Ela pode enfraquecer a singularidade do indivíduo - e também matá-la. Da maneira como a máquina é atualmente usada, 
ela não destrói a individualidade. $O$ ritmo mecânico é repetitivo, como os ritmos da natureza. Ele encontra seu lugar na natureza, mas não na vida humana de modo geral. Se o ritmo da natureza também fosse um ritmo humano, o homem seria ou uma espécie animal superior ou um ser dual, metade natural, metade não-natural: desequilibrado. Como um ser dual, ele jamais chegaria a uma condição de completa humanidade. $\mathrm{O}$ homem possui um ritmo que lhe é singular. Ele o contrapõe ao ritmo da natureza e cria seu próprio ambiente, em contraposição ao da natureza. $\mathrm{O}$ ritmo da máquina pode ser acelerado sem que nada se altere. $\mathrm{O}$ ritmo acelerado sem a contraposição da relação é devastador para o homem. A nova cultura deverá assimilar corretamente a máquina ao seu ritmo próprio. A máquina assim aperfeiçoada será indispensável à nova cultura, tanto quanto a natureza física sublimada o é ao homem.

A psicologia da forma é uma psicologia humana. Ela expressa a unidade do corporal como espiritual.A psicologia da formaé pura porquea forma é diretamente plástica - isso é possível porque atéa mais visível e exterior das formas pode ser aprofundada. O conhecimento integral da forma pode ser obtido mediante uma visão puramente objetiva, isto é, uma visão não obscurecida pela emoção subjetiva. Assim, a nova cultura, cuja mentalidade mantém a emoção profunda numa relação equivalente com a consciência (ou o intelecto), consegue discernir a forma, acentuá-la, destruí-la. Anova mentalidade nasceu de fato de um processo de aprofundamento empreendido pela velha cultura paralelamente a um fortalecimento físico. Sem a intensificação, ao mesmo tempo, de sua natureza física e de seu aspecto interior, o homem jamais alcançaria uma condição de plena humanidade. Temos sido, sempre e completamente, natureza física; devemos agora ser humanos. Na longa história da cultura, constatamos que o aspecto físico se torna cada vez menos "f́́sico" sem debilitar-se, enquanto o não-físico se torna consciente.

A culturaéuma força irresistivel na evolução humana. Ela às vezes avança em círculos, mas não erra nunca. Nossa mente, contudo, muitas vezes se equivoca. A velha cultura imaginava ser possível alcançar a plenitude da vida humana neste mundo fundindo o totalmente natural com o totalmente espiritual. E tentou atingir os dois, mas em vão. Além do fato de que o natural não é mais encontrável em seu estado perfeito, $o$ espiritual nunca pode ser expresso completamente, porque precisa ser externalizado para se tornar manifesto. Para o espírito, a externalização equivale à degradação. Por essa razão, o espiritual jamais pode aliar-se numa relação equilibrada ao que é inteiramente natural.

No princípio da cultura, o aspecto natural, embora imperfeito, domina a mente, enquanto o aspecto espiritual se restringe ao inconsciente. É o que vemos nas artes plásticas. Na forma, não há relação de igualdade entre opostos; a forma deve ser reduzida à dualidade dos dois pontos da linha reta para ser equilibrada. 
É preciso então que o aspecto natural perca seu poder sobre nossa mente, a qual consiste de um aspecto físico e de um espiritual. O físico deve ser transformado e o espiritual deve tornar-se consciente. A cultura aparentemente evolui em direções opostas: diminuindo o lado físico e intensificando o lado espiritual. A redução do físico significa, porém, a criação de outro aspecto físico, e não seu enfraquecimento. Poder-se-ia chamá-la de refinamento, embora isso possa causar equívocos. De todo modo, o lado físico precisa conservar seu funcionamento integral a fim de unir-se ao espírito consciente. No devido tempo, a cultura chegará a uma unidade completa, a humanidade total será obtida pela equivalência entre o material e o espiritual, e o equilíbrio se concretizará na vida real.

A forma determina o caráter particular de todas as coisas. Ela é "plástica", em virtude, primeiro, da natureza da superfície; segundo, por sua cor; terceiro, pela relação de posição; quarto, pela relação de tamanho.A expressão plástica da forma éfixa: imutável quando considerada fora do tempo; no tempo, tudo é mutável. Fora do tempo, todas as formas são igualmente belas; no tempo, há graus de beleza: o feio e o bonito. Fora do tempo, tudo é bom; no tempo, há o bem e o mal. Fora do tempo, a moral é imutável: no tempo, as formas de vida moral mudam. Fora do tempo, a psicologia é imutável; no tempo, as atitudes mentais do homem se modificame, portanto, a psicologia muda.É por isso que na cultura da forma os princípios morais podem basear-se na psicologia da forma, tal como Richet os fundamentou na psicologia ${ }^{6}$. Agora descobrimos que a base da forma não é imutável, como pensava a velha cultura. A nova cultura extingue a forma ao abolir a antiga moralidade. Mas a nova cultura não ficará sem princípios morais, porque a nova moralidade será baseada em relações universais.

Tempo é cultura, e a forma se modifica no curso da cultura. As formas mudam em ritmos variáveis. Assim, na velha cultura, as formas se associavam umas com as outras por meio de relações desiguais e, por conseguinte, desequilibradas. Só quando a variedade das formas aumenta de maneira uniforme, de modo a se estabelecerem relações equilibradas, é que elas podem anular-se pela diversidade. Nesse momento, a nova cultura vem à tona.

A fisionomia e a psicologia das formas são bem conhecidas e aceitas. Cada forma, cada linha e cada cor têm seu caráter e sua significação própria.A fisionomia não se refere unicamente à face. Pode-se estudar a manifestação mais exterior de uma forma como fisionomia abstraindo a psicologia da forma. A fisionomia é mais passível de erro, porque, na forma natural, muitas coisas ainda estão confusas ou desenvolvidas de modo incompleto. A beleza pode, assim, surgir em condições peculiares da natureza, as quais algumas vezes tendem para a perfeição a despeito de influências externas ou internas. No entanto, se nos fosse dado ver as formas em sua pureza, sem a influência de idéias con-
[6] Trata-se do iminente fisiologista francês Charles Richet (1850-1935), que também escreveu sobre questões de interesse humanitário. Ele é mencionado por Kandinsky em $O$ espiritual na arte. 
vencionais, elas revelariam seu conteúdo. A fisionomia e a psicologia pertencem à velha cultura, mas ainda são necessárias para preparar a nova e nos mostrar sua lógica. Os vários graus de abstração da forma propiciam uma imagem da evolução humana. É por isso que o estudo da forma tem importância hoje, mas não terá importância alguma na nova cultura. À medida que esta evolua, toda filosofia e toda arte se tornarão supérfluas. $O$ homem maduro será capaz de viver guiado pela intuição: todo "pensar e sentir através da forma" se dissolverá na unidade do intelecto com a emoção profunda.

Muitos modernos já se consideram nesse último estágio de desenvolvimento, mas ainda é muito cedo. Infelizmente, temos de continuar a fazer filosofia, a criar arte... a pensar e sentir pela forma.

O jazz e o neoplasticismo já estão criando um ambiente em que a arte e a filosofia se dissipam em um ritmo desprovido de forma, queé, por isso mesmo, "aberto".

No presente, quase sempre encontramos a interioridade e a exterioridade intensificadas separadamente. Num indivíduo, o não-físico se torna mais consciente, enquanto sua cultura exterior permanece subdesenvolvida; noutro, encontramos uma cultura mais exteriorizada, embora carente do espiritual. Assim, não há equilíbrio nem dentro dos indivíduos nem em suas relações mútuas. Por enquanto, é impossível vivenciar o ritmo universal.

Não se pode controlar diretamente a abstração e a abolição da forma na esfera espiritual com a mesma clareza com que o fazemos no plano das coisas materiais. O que quer que a cultura da forma inspire hoje na esfera mundana pode ter tamanha influência no espiritual quanto já o teve no plano material.

$\mathrm{Na}$ metrópole, inconscientemente e em resposta às necessidades da nova era, houve uma libertação da forma que levou ao ritmo livre, difundido por toda a grande cidade. Todos os estilos de construção, iluminação e propaganda colaboram para isso. O ritmo da metrópole, apesar de desequilibrado, cria a ilusão de ritmo universal, que é forteo suficiente para suplantar o velho ritmo. Catedrais, palácios e torres já não constituem o ritmo urbano. O ruído dos automóveis etc. contém relações de oposição, ao passo que os sinos das igrejas exibem apenas o ritmo da repetição. A nova cultura está sendo construída aqui, de modo inconsciente. Infelizmente, por um bom tempo ainda, o badalar dos sinos e muitos outros sinais nos farão lembrar da velha cultura.

Entretanto, o ritmo da metrópole expressa sonora e visualmente a opressão do trabalho. É possível notar a desigualdade entre a situação do trabalhador compulsório e a do indivíduo livre. Percebe-se a relação desequilibrada da luta pela sobrevivência: a tragédia do desequilíbrio entre o material e o moral. Ao equilibrar o material e o moral, a nova cultura engendrará uma metrópole totalmente nova, usando os mes- 
mos meios que a antiga cultura atualmente adota de maneira incorreta. O resultado disso será um novo ritmo de ver e ouvir: o trágico desaparecerá. O trágico, por sinal, já é bem menos visível na metrópole do que no campo, na aldeia ou na pequena cidade, graças, simplesmente, à destruição da forma.A "forma-como-particularidade" domina o meio rural e as cidades pequenas, onde o natural prevalece.

O jazz é alheio à opressão do trabalho. A orquestra toca como se estivesse brincando. $\mathrm{O}$ bar nos permite entrever o que a nova cultura irá introduzir de uma forma mais sublimada. Nesse momento a opressão do trabalho será desconhecida, como acontece atualmente no ambiente do bar. Ele nos oferece a oportunidade de vivenciar uma experiência pueril que desconcerta as pessoas da sociedade moderna com sua seriedade carrancuda (embora essas pessoas já sejam hoje menos "sérias" que as da geração anterior), pois elas opõem felicidade e seriedade: sorriem quando dançam e parecem sisudas quando cuidam de seus afazeres. No bar, porém, felicidadee seriedade formam um uno. Tudo ali está em equilíbrio, porque tudo se subordina ao ritmo. Não há vazio, não há tédio; o ritmo preenche tudo sem criar uma nova opressão - ele não se torna forma. Não subsiste nenhum laço com o antigo, pois no bar somente se vê e ouve o charleston. A estrutura do lugar, a iluminação e os anúncios - mesmo em seu estado de desequilíbrio - contribuem para arrematar o ritmo do jazz. Toda feiúra é sobrepujada pelo jazz e pela luz. Até a sensualidade é transcendida.

Livre da forma limitante, a sensualidade se abre. E a espiritualidade também. Os opostos agem do mesmo modo em suas esferas distintas. A sensualidade acentuada ao extremo é espiritualidade, e a espiritualidade consciente se expressa de modo sensual. No bar, a sensualidade não se acentua o suficiente: é refinada, mas não se espiritualiza.

Mais importante que tudo, o jazz cria o ritmo aberto do bar. $\mathrm{O}$ jazz aniquila. Tudo que abre executa uma ação aniquilante. Isso liberta o ritmo da forma e de tantas outras coisas que são forma sem ser reconhecidas como tal. Cria-se então um refúgio para aqueles que desejam se libertar da forma.

Tudo no bar se mexe e ao mesmo tempo permanece parado. A ação contínua controla a paixão. As garrafas e os copos nas prateleiras estão imóveis, mas se movimentam pela cor, pelo som, pela luz. Serão menos belos que as velas em um altar? Todos esses objetos têm a mesma forma abstrata: a altura maior que a largura. Os dançarinos de rostos maquiados mexem o corpo e param para descansar. Não há lugar para emoções individualizadas. A maquiagem e as roupas também são cultura; mas o bar reflete a falta de introspecção profunda de nossa cultura. Nele, toda propensão à individualidade cessa; só existem homens e mulheres. Todos dançam bem: todos fazem parte do mesmo ritmo. Beber tem outro sentido ali; não se bebe pelo prazer de 


\section{NOVOS ESTUDOS}

CEBRAP

82 , novembro 2008

pp. $181-189$ beber. Não se dança por interesse em uma mulher. Não há espaço para discutir negócios, política, dinheiro. Pois esses assuntos têm outro ritmo, fechado; um ritmo que se expressa na psicologia da forma por meio de uma multiplicidade de linhas diagonais - retas, mas desequilibradas, agitadas e fortuitas. No ambiente do bar, o ritmo natural adquire novo aspecto, desprovido dos caprichos da linha curva. Ele chega a ser hostil ao ritmo natural - que não exclui, porém, a linha flutuante, pois a fluidez está mais próxima do ritmo das emoções subjetivas: o curvilíneo está assim em harmonia com o ritmo da natureza, ainda que a própria natureza resista às vezes ao sentimento subjetivo. Básico em todos os ritmos é o ritmo das horizontais e verticais: por esse motivo, todas as coisas estão impregnadas de um elemento de repouso. Mas até mesmo esse ritmo introspectivo permanecerá "natural" se não for liberado pelas relações que aniquilam a forma, algo que o ritmo do jazz já está conseguindo fazer.

E por que no bar, especificamente? O povo ainda não amadureceu sua cultura; o burguês, apegado às convenções, menos ainda, e a aristocracia deveria tê-la cultivado. Os indivíduos de qualquer classe têm condições de manifestar uma cultura plenamente madura, formando um grupo dentro da massa. O indivíduo é explorado. O bar é uma exploração. Mas sem dinheiro a cultura não tem como se desenvolver. Mal usado ou bem usado, o dinheiro há de encontrar seu justo uso. $\mathrm{O}$ jazz é uma "atração". E, por isso, encontra-se agora no bar. 